Asian Journal of Information Technology 17 (3): 189-196, 2018

ISSN: $1682-3915$

(C) Medwell Journals, 2018

\title{
Power Quality Improvement in Wind Energy System Using Seven Level Shunt Active Filter
}

\author{
${ }^{1} \mathrm{~K}$. Ramesh and ${ }^{2} \mathrm{G}$. Tholkappia Arasu \\ ${ }^{1}$ Jayam College of Engineering and Technology, Nallanur, 636813 Dharmapuri, Tamil Nadu, India \\ ${ }^{2}$ AVS College of Technology, Attur Main Road, Chinnagoundapuram, \\ 636106 Salem, Tamil Nadu, India
}

\begin{abstract}
This research concentrates on improving the power quality in Wind Energy System (WES) using 3-phase, Seven Level-Shunt Active Filter (SL-SAF). In this background, the Permanent Magnet Synchronous Generator (PMSG) based $2.5 \mathrm{~kW}$ WES is considered to implement SL-SAF. The main intention of this SL-SAF is to improve the power quality in the proposed system when WES output changes with the wind speed and also to the variation in load. Moreover, it reduces the power loss during low wind velocity and also due to Total Harmonic Distortions (THD) with improved power factor. In this research, the proposed system performance parameters like output voltage, frequency and THD levels are analyzed for various wind velocities and unbalanced load conditions. Furthermore, the validity of SL-SAF is analyzed with intelligent Fuzzy Logic based Pulse Width Modulation (FL-PWM) techniques. The MATLAB/Simulink Software tool is employed for analyzing the performance of the proposed system. From the simulation results it has been evaluated and the relative results are used to validate the parameters of the SL-SAF converter.
\end{abstract}

Key words: Multi level inverter, non-linear load, Shunt Active Filter (SAF), Total Harmonic Distortion THD, Wind Energy System WES, Pulse Width Modulation (PWM), Fuzzy Logic Controller (FLC)

\section{INTRODUCTION}

In recent times, the power quality is becoming a serious issue in electrical systems due to extensive use of non-linear loads such as adjustable speed drives, uninterruptible power supply systems, battery charging system, etc. This equipment usually uses either diode or thyristor to realize power conversion on the basis of lower component cost and less control complexity. However, the converters to generate a large amount of harmonic current into the electrical supply system and the resulting harmonic distortion may leads to failure of sensitive equipment. In order to reduce the harmonic content in the system, the passive filters have been installed. Moreover, the harmonics are amplified and it may degrades the power quality of the system (Singh et al., 1999; Detjen et al., 2001; Soto-Sanchez and Green, 2001). Various active fltering approaches have been presented to address the harmonic issues in the power system (Babaei et al., 2014; Peng et al., 1990; Fujita and Akagi, 1998; Detjen et al., 2001; Ravindra et al., 2011). The active filters are proposed for compensating harmonic current and also to maintain power factor to the standard level.
However, the requirements of harmonic free current waveforms and good power factor, under non-sinusoidal voltage conditions are contradictory to each other. When the supply voltage is non-sinusoidal and connected to an unbalanced non-linear load any attempt to get harmonic free current by installing a shunt filter will result in a poor power factor. Similarly, any attempt to improve the power factor will result in distorted current waveforms. Under these conditions, an optimum performance is the best one can achieve. This study proposes a new scheme for balancing the currents and obtaining the best compromise between the power factor and current distortion under non-sinusoidal voltage conditions and it is discussed by Ravindra et al. (2011). In this context, the application of active filters, both series and shunt type have been widely researched by various groups. The context of application and the scheme is explained for identifying the harmonic content which varies from one scheme to the other by Peng et al. (1990), Fujita and Akagi (1998). Generally, a SAF employs a pulse width modulation based switching strategy for the inverter devices in order to dynamically counter the fundamental reactive component and also the harmonic components in the source current by Detjen et al. (2001) and Senini and Wolfs (2002). This

Corresponding Author: K. Ramesh, Jayam College of Engineering and Technology, Nallanur, 636813 Dharmapuri, Tamil Nadu, India 
target is obtained by implementing control algorithms of the reference current and a quick response procedure to get the control signal and simultaneously quick controlling dc-side capacitor voltage of the inverter as explained by Singh et al. (1998), Aredes and Watanabe (1995) and Rahmani et al. (2003a, b).

In this connection, various control algorithms like fuzzy logic controller and other intelligent controllers has been proposed by the researchers (Singh et al., 1998; Natarajan and Bensraj, 2013; Rahmani et al., 2002a, b; Gupta et al., 2015). The advantages of FLC over conventional controllers are that they do not need an accurate mathematical model, they can research with imprecise inputs can handle non-linearity and they are more robust than conventional nonlinear controllers. In this research fuzzy logic based PWM (FL-PWM) controller is implemented for shunt active power filter for the harmonics compensation under nonlinear loads.

\section{MATERIALS AND METHODS}

he power converters behave as nonlinear loads to ac supply system and cause harmonic injection, lower power-factor and poor voltage regulation in ac network. Moreover, single-phase loads on a three-phase supply system result in an unbalance in system voltage and supply current. The unbalance in voltage affects the performance of other loads which is connected to this system. The foresaid issues were discussed by many researchers and the implementation of active filters provided better results than conventional methods. Several filters were used to eliminate harmonics and lossless in the system using passive elements ( $\mathrm{L}$ and $\mathrm{C}$ ) or active elements like solid state Voltage Source Inverter (VSI) and Current Source Inverter (CSI).

Configuration of proposed wind energy system: In this research, the 3-bus WES test system is considered to implement and analyze the proposed SL-SAF using Matlab/Simulink Software tool. The system consists of a small wind turbine and the turbine is coupled with a PMSG.

In Fig. 1, the bus 1 and 3 have PMSG generator of $2.5 \mathrm{~kW}$ capacities, the generator output power changes with respect to different wind velocities and loading conditions. The oscillating generator output power is delivered to the load at bus 2 .

Mathematical model of the Permanent Magnet Synchronous Generator (PMSG): A Permanent Magnet

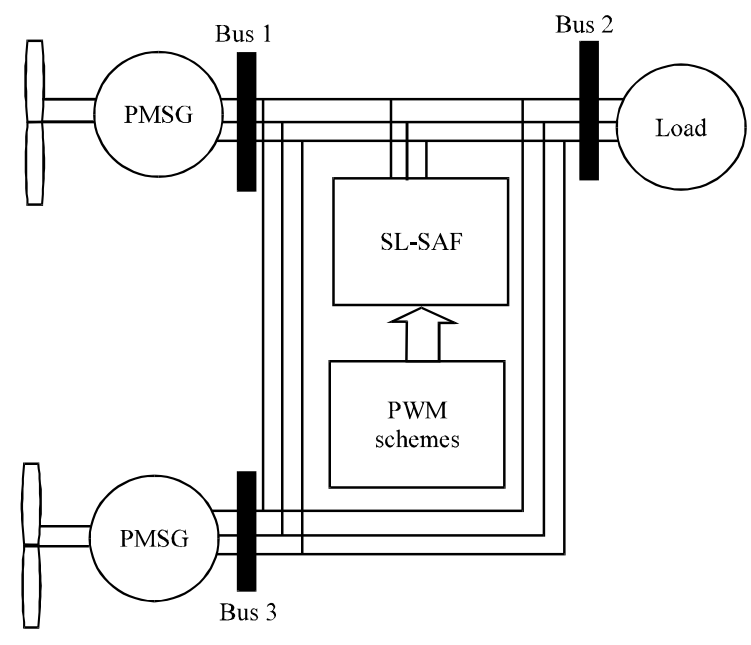

Fig. 1: Proposed WES system configuration

Synchronous Generator (PMSG) rated $2.5 \mathrm{~kW}, 440 \mathrm{~V}$ and rated speed $600 \mathrm{rpm}$ is employed in the Wind Energy System (WES). The output voltage of the generator varies with respect to the wind speed variation. The equation number Eq. 1 shows the mechanical output power of the wind turbine and it is given by cube law:

$$
\mathrm{P}_{\mathrm{W}}=\frac{1}{2} \rho \mathrm{SV}_{\mathrm{W}}^{3} \mathrm{C}_{\mathrm{P}} \lambda
$$

Where:

$$
\begin{array}{ll}
\rho & =\text { The air density }\left(\mathrm{kg} / \mathrm{m}^{3}\right) \\
\mathrm{S} & =\text { The surface of the turbine blades } \\
\left(\mathrm{m}^{2}\right) \text { and } \mathrm{V}_{\mathrm{W}} & =\text { The average wind velocity }(\mathrm{m} / \mathrm{sec}) \\
\mathrm{C}_{\mathrm{p}} & =\text { The power coefficient }
\end{array}
$$

Equation 2 gives the tip speed ratio function:

$$
\lambda=\frac{\omega_{\mathrm{m}} \cdot \mathrm{R}}{\mathrm{V}_{\mathrm{W}}}
$$

Where:

$\omega_{\mathrm{m}}=$ The rotor mechanical speed $(\mathrm{rad} / \mathrm{sec})$

$\mathrm{R}=$ The blade radius

Equation 3 shows the wind turbine output torque $T_{w}$ :

$$
\mathrm{T}_{\mathrm{W}}=\frac{\mathrm{P}_{\mathrm{W}}}{\omega_{\mathrm{m}}}=\frac{\frac{1}{2} \rho \mathrm{SV}_{\mathrm{W}}^{3} \mathrm{C}_{\mathrm{P}} \lambda}{\lambda}
$$

The line to line voltage of an ideal (unloaded and loss-less) PMSG is given in Eq. 4 as follows:

$$
\mathrm{V}_{\mathrm{L}}=\mathrm{K}_{\mathrm{V}} \omega_{\mathrm{e}} \sin \left(\omega_{\mathrm{e}} \cdot \mathrm{t}\right)
$$


Where:

$\mathrm{K}_{\mathrm{V}}=$ The voltage constant

$\omega_{\mathrm{e}}=$ The electrical frequency related to the mechanical speed

$\omega_{\mathrm{m}}=$ The relation

$$
\omega_{\mathrm{e}}=\omega_{\mathrm{m}} \cdot\left(\frac{\mathrm{N}_{\mathrm{P}}}{2}\right)
$$

where, $N_{p}$ is the number of poles of PMSG. The mathematical expressions from Eq. 1-5 are used to develop the MATLAB/Simulink Model. In simulation model, the 3-phase PMSG is considered which provides maximum power of $2.5 \mathrm{~kW}$ at wind velocity of $12 \mathrm{~m} / \mathrm{sec}$. The voltage rating is about $440 \mathrm{~V}$ when speed of generator nearly $600 \mathrm{rpm}$. The speed of the generator changes from $160-560 \mathrm{rpm}$ at various wind velocities.

Configuration of SL-SAF system: The Seven Level Shunt Active Filter (SL-SAF) is proposed to improve the quality output voltage in the test system. The power rating of Voltage Source Inverters (VSIs) is not capable to carry out the huge and sudden changes in the load. This may affect system voltage level and generated harmonics to the system. The multilevel inverter is designed to generate nearly sinusoidal output voltage waveform and to eliminate $\mathrm{THD}$. A key concern in the fundamental switching scheme is to determine the switching angles in order to generate the voltage with fundamental frequency.

In Fig. 2, the proposed 3-phase SL-SAF inverter topology is illustrated. The numbers of output voltage levels $\left(\mathrm{N}_{\text {level }}\right)$ of the generated Voltage $(\mathrm{V})$ are calculated from Eq. 6 and 7. The voltage level equations are expressed as follows:

$$
N_{\text {level }}=2^{2 n+1}-1
$$

where, $\mathrm{n}=1$. Hence:

$$
\mathrm{N}_{\text {level }}=7
$$

Modulation index:

$$
\mathrm{MI}=\frac{2 * \mathrm{~A}_{\mathrm{m}}}{\left(\mathrm{N}_{\text {level }}-1\right) * \mathrm{~A}_{\mathrm{c}}}
$$

Where:

$\mathrm{A}_{\mathrm{m}}=$ Amplitude of modulating wave

$\mathrm{A}_{\mathrm{c}}=$ Amplitude of carrier

$\mathrm{N}_{\text {level }}=$ Number of voltage levels

The modulation index of the SL-SAF is varied as per Eq. 8 in PWM signal of fixed $10 \mathrm{kHz}$ frequency to reduce harmonic content. The generated signal will provide the voltage level required and also eliminate the harmonics in the proposed system.

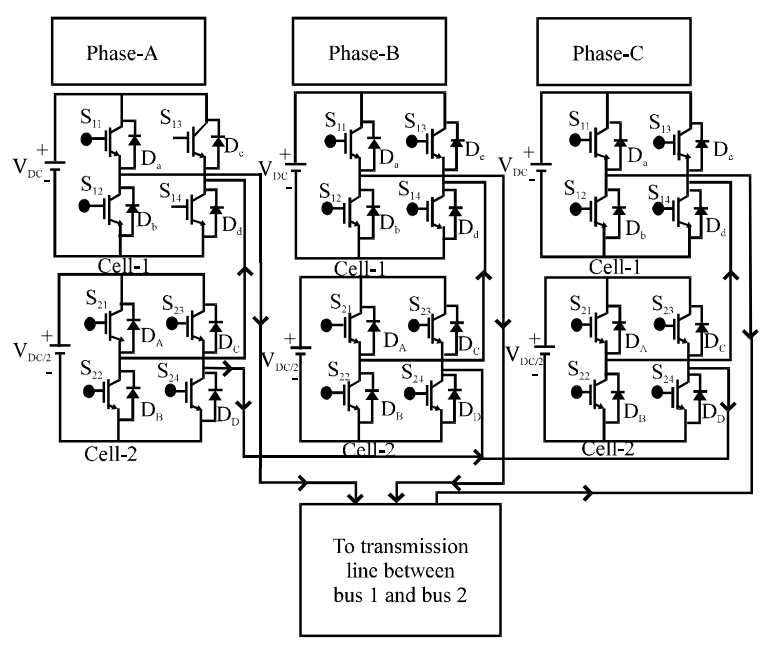

Fig. 2: Proposed 3-phase seven level-SAF inverter

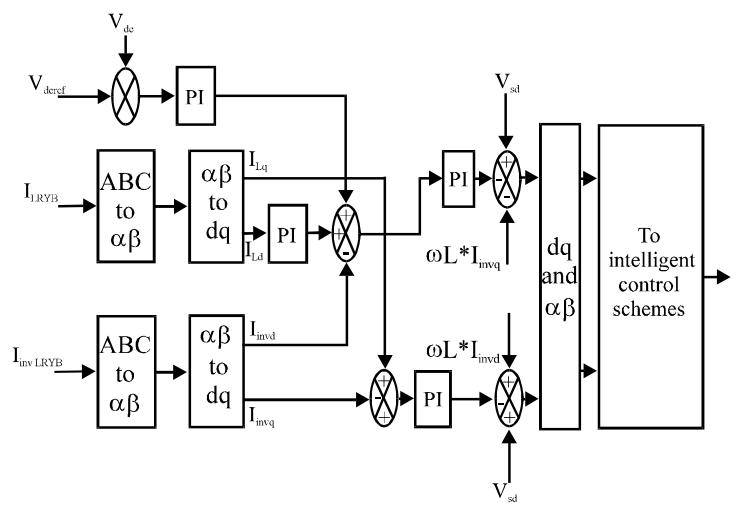

Fig. 3: PWM control structure for SL-SAF

Control schemes for SL-SAF: In this control method, PWM pulse is generated to control the shunt active filter (Inverter). The three phase load current has been considered and it is converted into $\alpha \beta$ and dq0 using Park and Clarke transformation. This dq0- axis indicates the active, reactive and reference components of the three phase currents, respectively.

The difference in active component from the load current and shunt converter current has been compared with the difference in reactive components of the both proposed SAF converter and load currents. This comparison will provide the available active and reactive current to overcome the requirement.

The proposed control structure for SL-SAF has been illustrated in Fig. 3. The PWM signal is generated by converting this resultant dq0 component into three phases $(\mathrm{ABC})$ component using inverse park and clarke transformation. The generated three phase reference signal with $(\alpha \beta)$ and voltage magnitude is used to select suitable switching sector of a SL-SAF inverter using fuzzy based PWM control schemes. 
Fuzzy logic implementation: Various control algorithms are discussed for controlling the pulse width in (Detjen et al., 2001). In this research, fuzzy logic controller is used for finding suitable MI to the PWM signal. It is not necessary to design the fuzzy controller if the mathematical model of the system is known.

In the membership function, seven linguistic values, \{Negative Big (NB), Negative Middle (NM), Negative Small (NS), Zero (ZE), Positive Small (PS), Positive Middle (PM), Positive Big (PB) \}. The output variable u (the control value) which also have seven linguistic values Negative Big (NB), Negative Middle (NM), Negative Small (NS), Zero (ZE), Positive Small (PS), Positive Middle (PM), Positive Big (PB)\}.

The main objective function is proposed in Eq. 8, based on that the fuzzy controller has been designed and the corresponding fuzzy sets are presented in Table 1, based on the defined linguistic values. The structure of fuzzy logic controller is shown in Fig. 4. There are 49 consequent rules for this fuzzy controller is implemented to control the output voltage level and also to reduce THD in the system. In Fig. 5, the input and output membership function for proposed FL-PWM is illustrated. The membership function range of the input 1 (E) and input $2(\mathrm{CE})$ is $[-100,+100]$. The corresponding Modulation Index (MI) output from the FLC is varies from $0.4-1$.

Table 1: Fuzzy logic rules to select MI

\begin{tabular}{llllllll}
\hline $\mathrm{CE} / \mathrm{E}$ & $\mathrm{NB}$ & $\mathrm{NM}$ & $\mathrm{NS}$ & ZE & PS & PM & PB \\
NB & ZE & NB & NB & PM & ZE & ZE & PM \\
NM & NB & NB & NM & PS & ZE & ZE & PM \\
NS & NB & NS & NS & PS & ZE & ZE & PS \\
ZE & NB & NS & NS & ZE & PS & PB & PB \\
PS & NS & NS & ZE & PS & PB & PB & PB \\
PM & NS & ZE & PS & ZE & PM & PB & PM \\
PB & NM & ZE & ZE & NS & ZE & PS & ZE \\
\hline
\end{tabular}

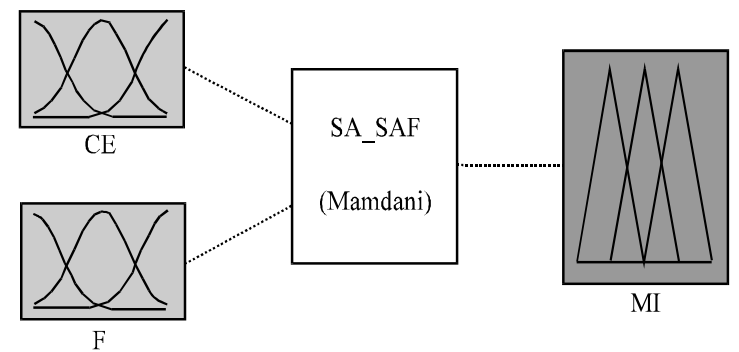

Fig. 4: Structure of fuzzy logic controller
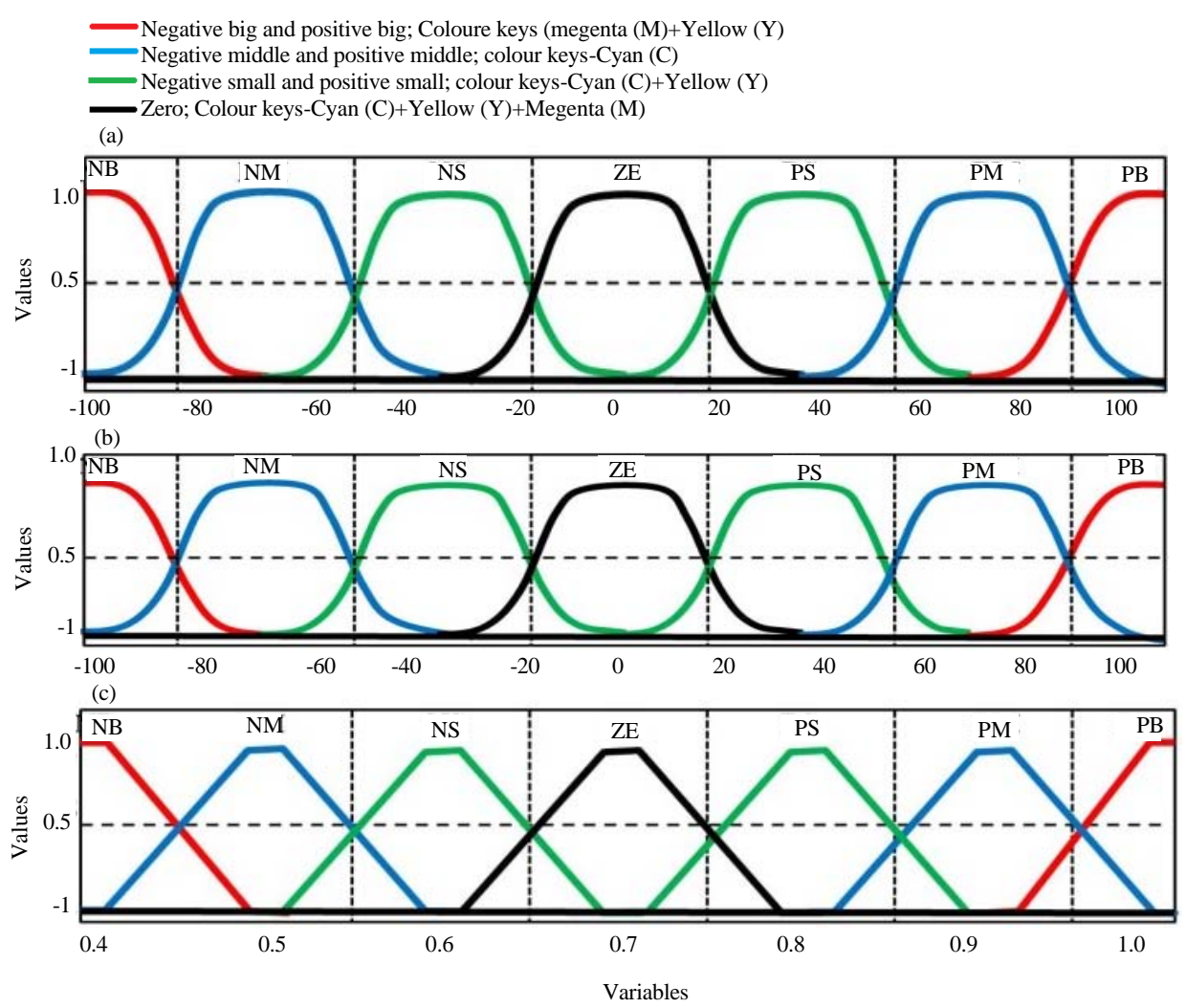

Fig. 5: Input and output membership function for proposed FL-PWM: a) Input variable "E"; b) Input variable "CE" and c) Input variable "CM" 


\section{RESULTS AND DISCUSSION}

In Fig. 6, the MATLAB/Simulink Model of the proposed SL-SAF with FL-PWM is illustrated. The proposed system is modeled using various parameters such as PMSG, SL-SAF, non linear load, induction motors and etc., The modeling parameters of induction motor, 3-phase resistive load and diode bridge rectifier are indicated in Table 2 . The proposed system configuration is tested for various loads such as squirrel cage induction motor, uncontrolled diode bridge rectifier with resistive load and three phase star connected loads. The control and performance of the system is analyzed with and without shunt active filter. The results have been compared for both conditions.

This simulink model shows the three phase supply system associated with the non-linear loads such as squirrel cage induction motor, diode bridge rectifier and star connected load. Due to the non-linear load characteristics the system will drawn different currents from the system. This non-linear load also injects the harmonics in the system. This will leads to poor power factor and high THD content.

The results of the proposed system without shunt active filter is indicated in the Fig. 7a, b. It indicates the seven level converter current waveforms and individual phase current waveforms. This harmonic spectrum shows the fundamental current of $25 \mathrm{~A}$ in magnitude. There is no even order harmonic present in this system. So the effect of even order harmonic is vanished. But it contains the 5 A of DC component.

In Fig. 8, the current waveform due to unbalanced load conditions and injected current waveform using SL-SAF under load disturbance and also the regulated waveform current at the load are shown. This output is passed through RLC elements to get the pure sinusoidal waveform and also to maintain regulated current waveform at the load. The amount of THD generated in the system before and after SL-SAF compensation is given in Table 3 .

Table 2: Simulink parameters of non-linear loads

\begin{tabular}{ll}
\hline Variables & Values \\
\hline SL-SAF parameter & \\
DC source $\left(\mathrm{V}_{\mathrm{dc}}\right)$ & $100 \mathrm{~V}$ \\
Parameters of Induction motor & \\
Machine type & Wound rotor \\
Power rating & $4 \mathrm{kVA}$ \\
Supply voltage & $400 \mathrm{~V}$ \\
Frequency & $50 \mathrm{~Hz}$ \\
Rated speed & $1500 \mathrm{rpm}$ \\
Stator resistance & $1.405 \Omega$ \\
Stator inductance & $5.839 \mathrm{mH}$ \\
Rotor resistance & $1.395 \Omega$ \\
Rotor inductance & $5.839 \mathrm{mH}$ \\
Mutual inductance $(L m)$ & $0.1722 \mathrm{H}$ \\
Parameters of 3-phase resistive load & \\
Connection type & $S \operatorname{Star}$ connected \\
Resistance $\left(\mathrm{R}_{\mathrm{e}}\right.$ and $\left.\mathrm{R}_{\mathrm{c}}\right)$ & $50 \Omega$ \\
Resistance $\left(\mathrm{R}_{\mathrm{b}}\right)$ & $100 \Omega$ \\
Uncontrolled diode bridge rectifier & \\
Resistance $\left(\mathrm{R}_{\mathrm{L}}\right)$ & $50 \Omega$ \\
\hline
\end{tabular}

Table 3: Harmonic analy sis before and after SL-SAF compensation

\begin{tabular}{lcc} 
& Before compensation & After compensation \\
Values & Current magnitude (A) & Current magnitude (A) \\
\hline 1st & 28.000 & 25.000 \\
3rd & 0.1507 & 0.0316 \\
5th & 0.4520 & 2.6490 \\
7th & 0.3160 & 1.1790 \\
9th & 0.0303 & 0.0125 \\
11th & 0.2808 & 0.9356 \\
13th & 0.0048 & 0.5424 \\
15th & 0.3177 & 0.0084 \\
17th & 0.2612 & 0.4686 \\
19th & 0.0245 & 0.2836 \\
\hline
\end{tabular}

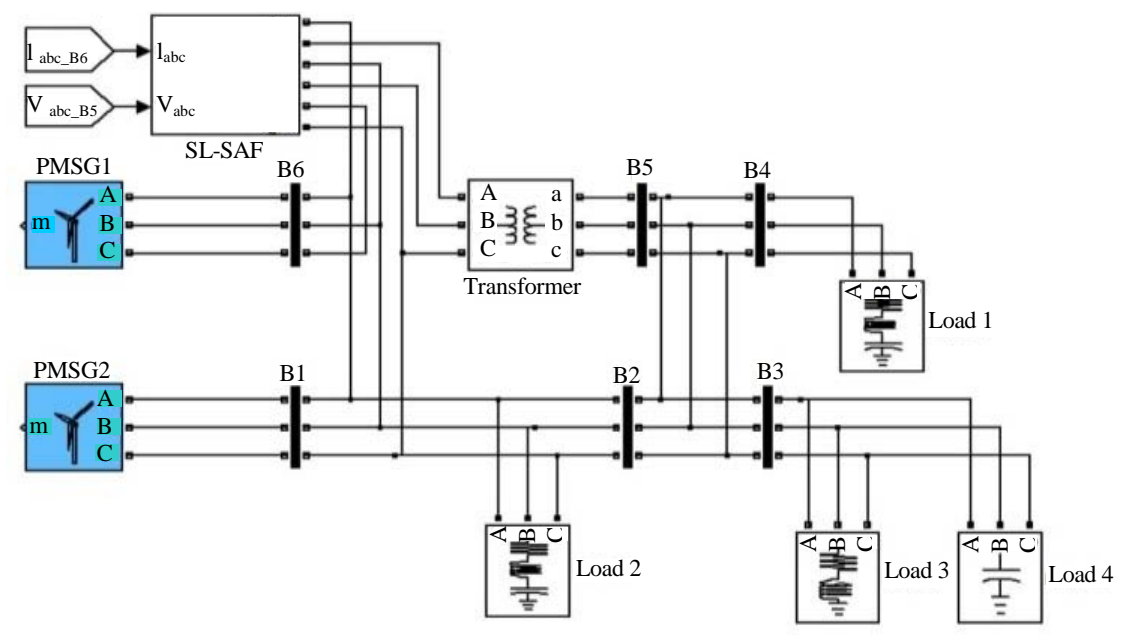

Fig. 6: Simulink model of proposed WES with SL-SAF (permanent magnet synchronous generator-colour key; Cyan (C)) 

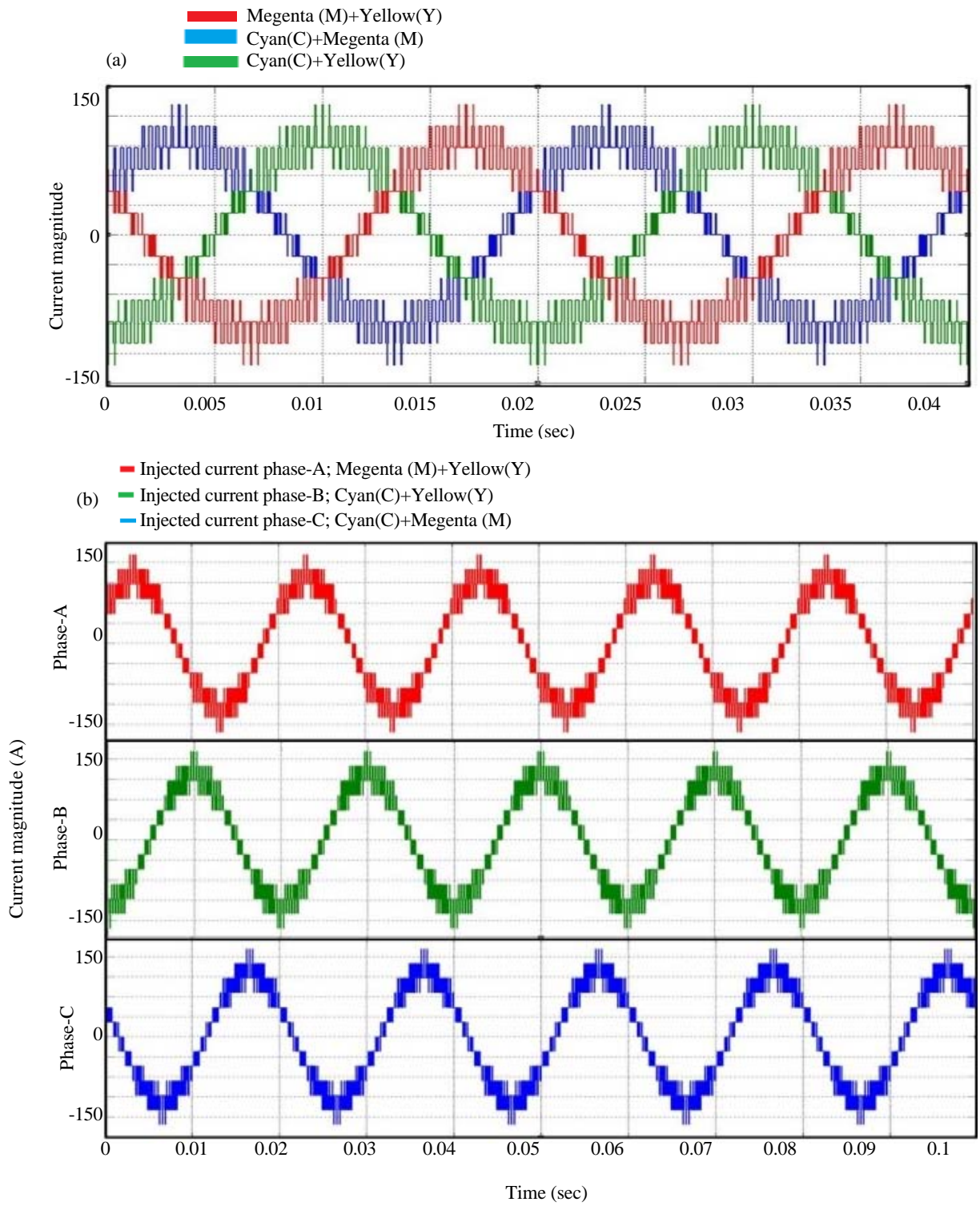

Fig. 7: a) Seven level converter current waveform and b) Individual phase current waveforms

The harmonic spectrum for Non-linear load without and with SL-SAF (MI = 1) are shown in the Fig. 9 and 10. The effect of 5 th order harmonic is higher than that of other odd order harmonics. The system has $13.82 \%$ current THD before implementation of SL-SAF compensation. This \% THD level is compensated and reduced into $4.307 \%$ after implementation of SL-SAF with fuzzy logic based PWM. Similarly \%THD analysis has been carried out for various load conditions. The fuzzy logic PWM with SL-SAF improves the power factor in the wind energy system and also reduces the \%THD by tuning the modulation index of PWM signal. The simulation results of SL-SAF with conventional PWM and SL-SAF with fuzzy based PWM has been compared and presented in the Table 4.

From the Fig. 9 and 10, it is found that, the power factor in the proposed WES system has been improved as per the IEEE-519 recommended practices and requirements for harmonic control in electrical power systems. Furthermore, after implementation of SL-SAF with fuzzy based PWM the power factor is improved to the standard level (nearly 0.9). The total harmonic content in the system under various loading conditions has been reduced by tuning $\mathrm{MI}$ of the PWM signal with the help of FL-PWM. 


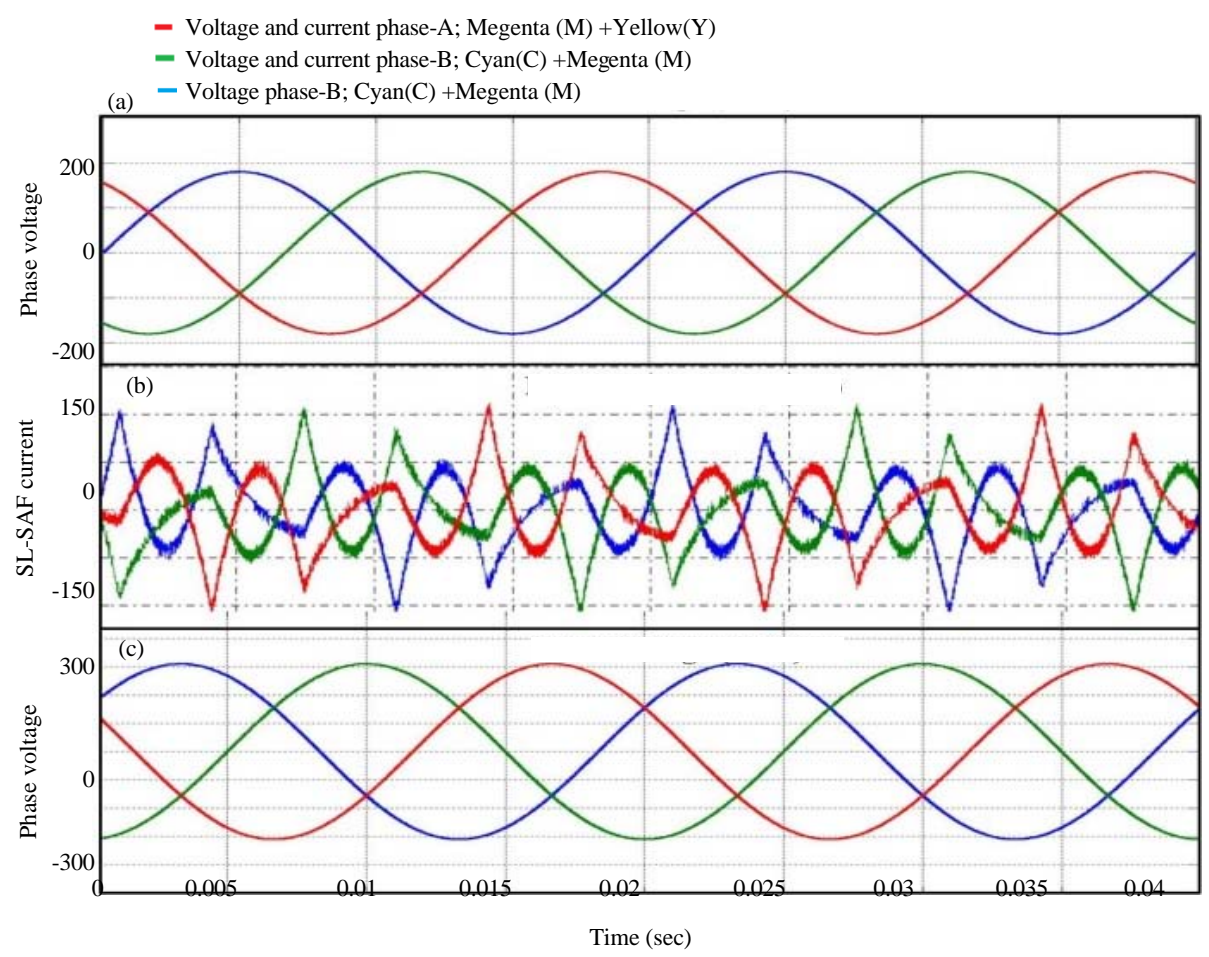

Fig. 8: SL-SAF injected current waveform under load disturbance: a) Injected current (A) and b) Load Voltage (V)

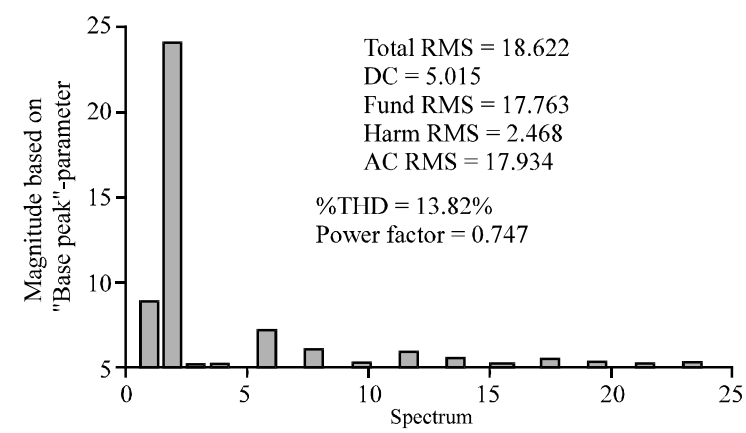

Fig. 9: Harmonic spectrum for non-linear load without SL-SAF $(\mathrm{MI}=1)$

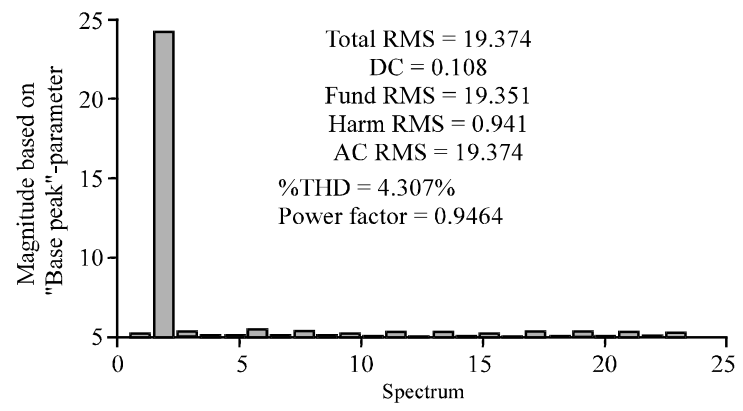

Fig. 10: Harmonic spectrum for non-linear load without SL-SAF $(M I=1)$

\begin{tabular}{lcc}
\multicolumn{2}{l}{ Tabel 4: Comparison of THD\% for various MI } \\
\hline \\
THD (\%) & \\
Modulation & SL-SAF with & $\begin{array}{c}\text { SL-SAF with } \\
\text { fuzzy based }\end{array}$ \\
Index (MI) & conventional PWM & 4.307 \\
1 & 13.82 & 4.358 \\
0.9 & 12.93 & 4.923 \\
0.8 & 10.66 & 5.030 \\
0.7 & 11.61 &
\end{tabular}

\section{CONCLUSION}

The conventional SAF with traditional PWM control is simple and gives required output levels. But, it gives a considerable ripple in the output with lower order harmonics. In this study discussed about a new SL-SAF inverter mitigate the THD in the proposed WES. The FL-PWM controller is implemented to optimize the suitable Modulation Index (MI). From the simulation results, it has been observed that the voltage ripple and current $\% \mathrm{THD}$ is reduced to $4.3 \%$ under various load disturbance and unbalanced load conditions. The simulation study also highlights that the proposed SL-SAF with FL-PWM method which gives good control over the power quality of the system. In summary, the power quality improvement was completed by employing SL-SAF in WES through the reduction of THD and enhancement in power factor to the standard level as compared to the existing system. 


\section{REFERENCES}

Aredes, M. and E.H. Watanabe, 1995. New control algorithms for series and shunt three-phase four-wire active power filters. IEEE Trans. Power Delivery, 10: 1649-1656.

Babaei, E., S. Alilu and S. Laali, 2014. A new general topology for cascaded multilevel inverters with reduced number of components based on developed H-bridge. IEEE. Trans. Ind. Electron., 61: 3932-3939.

Detjen, D., J. Jacobs, D.R.W. Doncker and H.G. Mall, 2001. A new hybrid filter to dampen resonances and compensate harmonic currents in industrial power systems with power factor correction equipment. IEEE. Trans. Power Electron., 16: 821-827.

Fujita, H. and H. Akagi, 1998. The unified power quality conditioner: The integration of series-and shunt-active filters. IEEE. Trans. Power Electron., 13: 315-322.

Gupta, U.D., P. Das and M.A. Hoque, 2015. A fuzzy controlled shunt active power filter for reducing current harmonics and reactive power compensation. Proceedings of the 2015 International Conference on -Electrical Engineering and Information Communication Technology (ICEEICT), May 21-23, 2015, IEEE, Bangladesh, ISBN:978-1-4673-6676-2, pp: $1-5$.

Natarajan, S.P. and R. Bensraj, 2013. A new three phase seven level asymmetrical inverter with hybrid carrier and stepped reference. Intl. J. Comput. Appl., 61: 22-28.

Peng, F.Z., H. Akagi and A. Nabae, 1990. A new approach to harmonic compensation in power systems-a combined system of shunt passive and series active filters. IEEE Trans. Ind. Applic., 26: 983-990.

Rahmani, S., K. Al-Haddad and F. Fnaiech, 2002. A series hybrid power filter to compensate harmonic currents and voltages. Proceedings of the IEEE 2002 28th Annual Conference on Industrial Electronics Society IECON-02, Vol. 1, November 5-8, 2002, IEEE, Tunisia, North Africa, ISBN:0-7803-7474-6, pp: 644-649.
Rahmani, S., K. Al-Haddad and F. Fnaiech, 2003a. A new indirect current control algorithm based on the instantaneous active current for reduced switch active filters. Proceedings of the 10th European Conference on Power Electronics and Applications EPE, September 2-4, 2003, Taylor \& Freancis Group, Toulouse, France, pp: 3-3.

Rahmani, S., K.A. Al-Haddad and F. Fnaiech, 2003b. A new control technique based on the instantaneous active current applied to shunt hybrid power filters. Proceedings of the 2003 IEEE 34th Annual Conference on Power Electronics Specialist PESC'03, Vol. 2, June 15-19, 2003, IEEE, Tunisia, North Africa, ISBN:0-7803-7754-0, pp: 808-813.

Ravindra, S., V.V. Reddy and S. Sivanagaraju, 2011. Design of shunt active power filter to eliminate the harmonic currents and to compensate the reactive power under distorted and or imbalanced source voltages in steady state. Intl. J. Eng. Trends Technol., 2: 20-24.

Senini, S.T. and P.J. Wolfs, 2002. Systematic identification and review of hybrid active filter topologies. Proceedings of the 2002 IEEE 33rd Annual Conference on Power Electronics Specialists PESC-02, Vol. 1, June 23-27, 2002, IEEE, Australia, ISBN:0-7803-7262-X, pp: 394-399.

Singh, B., K. Al-Haddad and A. Chandra, 1999. A review of active filters for power quality improvement. IEEE Trans. Ind. Electron., 46: 960-971.

Singh, B.N., A. Chandra and K. Al-Haddad, 1998. Performance comparison of two current control techniques applied to an active filter. Proceedings of the 8th International Conference on ICHQP-98, Harmonics And Quality of Power, Oct. 14-18, Athens, Greece, pp: 133-138.

Soto-Sanchez, D.E. and T.C. Green, 2001. Voltage balance and control in a multi-level unified power flow controller. IEEE Trans. Power Delivery, 16: 732-738. 